\title{
A Study of Correlation between Dermatoglyphic Angle and Blood Pressure
}

\author{
Zeenat Akhtar ${ }^{1}$, Vishal Verma², Reena Singla ${ }^{3}$ \\ ${ }^{1}$ Department of Anatomy, MMIMSR, MMDU, Mullana, Ambala, Haryana, India. ²Department of Anatomy, MMIMSR, \\ MMDU, Mullana, Ambala, Haryana, India. ${ }^{3}$ Department of Anatomy, MMIMSR, MMDU, Mullana, Ambala, Haryana, India.
}

\section{ABSTRACT}

\section{BACKGROUND}

To resolve the biomedical problems, palmar dermatoglyphics has been used as a method. For the screening of hypertension palmar prints can be used. We wanted to determine the correlation between dermatoglyphic angle and blood pressure.

\section{METHODS}

This is a cross sectional study. Palmar prints of right and left hands were taken with the help of inkpad. Blood pressure was also measured and ATD angle of both the hands were measured with the help of goniometer in 200 females and 200 male subjects of North India. Percentages, Pearson's chi-square test, Student independent $\mathrm{t}$ test, one-way ANOVA were used. A p value $<0.05$ was considered statistically significant. Statistical analysis was conducted using SPSS version 20.

\section{RESULTS}

Hypertension I and II were recorded for $7.0 \%$ (6.0\% of males and $6.0 \%$ of females) and $2.3 \%$ subjects (3.0\% of males and $1.5 \%$ females). Overall $28.3 \%$ of subjects had prehypertension. A statistically significant difference was observed in the value of left hand ATD angle for the comparison of hypertensive and non-hypertensive subjects.

\section{CONCLUSIONS}

Dermatoglyphics can be used as a tool for the prediction of various diseases with a genetic link. Several studies nowadays show association of dermatoglyphic angle with hypertension.

\section{KEY WORDS}

Dermatoglyphics, Blood Pressure, ATD Angle
Corresponding Author:

Dr. Vishal Verma

Department of Anatomy,

MMIMSR, MMDU,

Mullana, Ambala-133207,

Haryana, India.

E-mail: drvishalverma03@gmail.com

DOI: $10.14260 /$ jemds/2020/224

Financial or Other Competing Interests: None.

How to Cite This Article:

Akhtar Z, Verma V, Singla R. A study of correlation between dermatoglyphic angle and blood pressure. J. Evolution Med. Dent. Sci. 2020;9(13):1040-1044, DOI: $10.14260 /$ jemds/2020/224

Submission 24-01-2020, Peer Review 07-03-2020, Acceptance 13-03-2020, Published 30-03-2020.

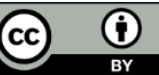




\section{BACKGROUND}

Dermatoglyphics is the study of epidermal ridges and their configuration on the palmar region of hand and fingers as well as in the plantar region of feet and toes. This word is derived from the Greek word "Derma" meaning "Skin" and "glyphic" meaning curved. JCA Mayoff in 1780 was the first to write that basic Jenets of fingerprint analysis and concluded that dermatoglyphic pattern is never same in two individuals. It is also established by Galton that the skin ridge patterns are permanent. Genetic and environmental factors are found to influence the formation of dermal pattern.(1) These factors are also involved in the multifactorial aetiology behind hypertension. Therefore many studies are now being conducted so as to establish the correlation between dermatoglyphic patterns and blood pressure, not only this association of dermatoglyphic pattern with many other diseases like Congenital Heart Disease, Leukemia and Idiopathic Mental Retardation has developed.(2) Prehypertension and hypertension are recognized as a leading cause of morbidity and mortality across the world. These are regarded as silent killers as they causes no symptoms or quite few in late stages.(3) Only $30 \%$ of the individuals would have the disease are aware of It.(4) If not detected or left uncontrolled, these can lead to life threatening complications like heart disease, stroke, kidney problems and blindness over a duration of years. Hypertension is not attributable to single cause rather it reflects the interaction of multiple genetics and environmental factors, so that siblings of affected parents have higher chances of developing it in later life.(5) Several studies are nowadays showing association of dermatoglyphic traits with hypertension. This can be of great utility for clinical point of view if these dermatoglyphic markers could be used to screen individuals at higher risk of developing hypertension. $(6,7,8,9)$ Several studies report hypertension individuals to be having larger ATD angles. $(9,10,11)$ Few studies reported smaller ATD angles also among Hypertension subjects. ${ }^{12,13,14)}$ These differences can be because of the differences in the method employed, pressure applied during printing and whether fingers are closely approximated or splayed.(15)

\section{METHODS}

Present study was conducted in Department of Anatomy, MMIMSR Mullana (Ambala). The study includes 400 subjects (200 males, 200 females )in the age group of $17-40$ yrs. who were mainly students and employees of MMIMSR, of district Ambala, Haryana, North India. Proper informed consent was taken from the subjects and IEC clearance was also taken.

Subjects were in the age group of 18-40 years. Subjects having problem in standing erect, postural defects or confined to wheelchair, skin disease like leprosy, eczema, inflammation or trauma of hand were excluded. Goniometer and stamp pad, weighing-scale, black ink and magnifying lens were used in the present study for the measurement of TAD angle and for taking palm prints. Bodyweight of all subjects were recorded on weighing-scale after standardizing it to 0.00 , bare footed and with minimal clothes. Recordings were done in kilograms nearest to first decimal. Height was measured in centimeters and converted to meters nearest to decimal.

Blood pressure was recorded by using mercury sphygmomanometer and stethoscope. Subjects were made comfortable and relaxed. Appropriate cuff size was taken which was encircling around $80 \%$ of arm circumference. 2 successive readings were taken with at least 5 minutes interval. Higher of the two readings was considered. Blood pressure reading was taken after 1 hour, if the reading turned out to be below or beyond the normal rang. Patients were considered hypertensive based on their blood pressure recordings, present and past medical history, and history of medications. The subjects were grouped as per JNC $7^{\text {th }}$ report. (16)

Normal: $<120 /<80 \mathrm{mmHg}$.

Prehypertension: 12-139/80-89 mmHg.

Hypertension I: 140-159/ 90-99 mmHg.

Hypertension II: >160/>100 mmHg.

\section{Palmar Printing Using Ink Method}

Entire palm was covered using as ink pad. Palm was pressed down firmly, and pressure applied on the back of palm so that center is printed without any space on a paper sheet. He paper was placed on the edge of flat surface and fingers were printed by rolling them. With the help of magnifying glass palm prints were observed. For present study following landmarks were considered. Digital and axial triradii must be present. No space present in the center of palm, all the fingertip area must be present and digital wrist creases must be located.

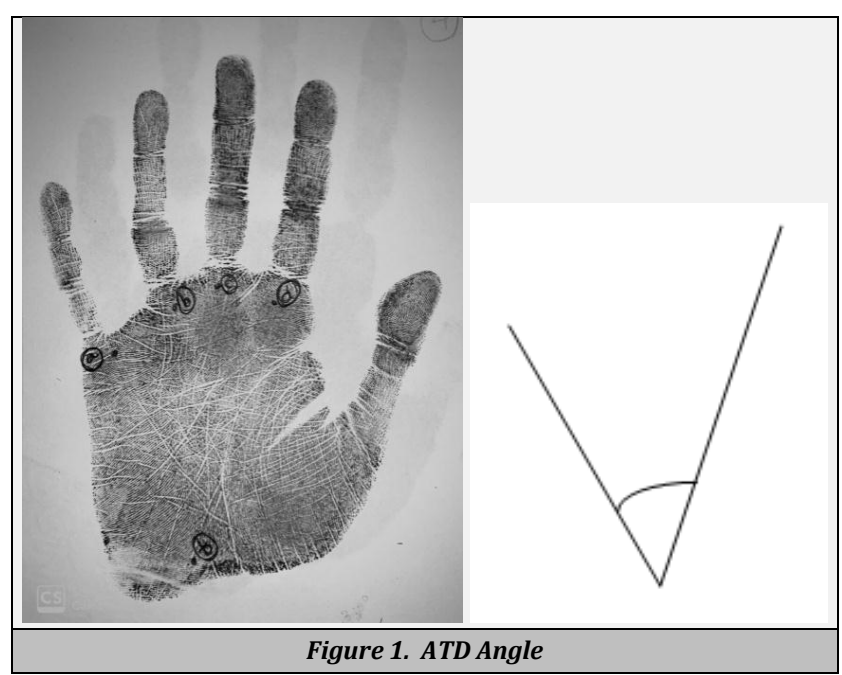

Observations

1. Axial and digital triradii in the palm.

2. By drawing lines connecting triradii A, D to T, ATD angle was determined by goniometer.

\section{Statistical Analysis}

Percentages, Pearson's chi-square test. Student independent t test, one-way ANOVA, $\mathrm{P}$ value $<0.05$ was considered Statistically significant, analysis was conducted using statistical package for social sciences "SPSS version 20 ". 


\section{RESULTS}

The results were presented in terms of mean \pm standard deviation for quantitative data and frequency distribution were presented in simple percentages. For determining statistical significance of difference among various variables qualitative data was 1042 analysed by Pearson's chi-square test and quantitative data by student's independent $t$ test and one-way ANOVA. P value of $<0.05$ was considered significant. All analysis was done using "SPSS version 20"

\begin{tabular}{|cccc|}
\hline & Minimum & Maximum & Mean \pm SD \\
Age & 17 & 40 & $22.25 \pm 5.84$ \\
Weight $(\mathrm{Kg})$ & 35 & 112 & $59.47 \pm 14.44$ \\
Height $(\mathrm{cm})$ & 146 & 191 & $163.17 \pm 8.80$ \\
BMI $\left(\mathrm{Kg} / \mathrm{m}^{2}\right)$ & 15.15 & 35.19 & $22.17 \pm 4.10$ \\
Waist circumference $(\mathrm{cm})$ & 51 & 120 & $82.32 \pm 14.02$ \\
Hip circumference $(\mathrm{cm})$ & 54 & 128 & $91.23 \pm 15.72$ \\
Waist hip ratio & 0.63 & 1.43 & $0.91 \pm 0.15$ \\
Waist height ratio & 0.20 & 0.75 & $0.50 \pm 0.08$ \\
\hline \multicolumn{4}{|c|}{ Table 1. Descriptive Statistics of Age and } \\
Anthropometric Measures of Study Subjects \\
\hline
\end{tabular}

\begin{tabular}{|cccc|}
\hline Blood Pressure & Males & Females & Total \\
Normal & $120(60.0 \%)$ & $130(65.0 \%)$ & $250(62.5 \%)$ \\
Pre-Hypertension & $62(31.0 \%)$ & $51(25.5 \%)$ & $113(28.3 \%)$ \\
Hypertension-I & $12(6.0 \%)$ & $16(8.0 \%)$ & $28(7.0 \%)$ \\
Hypertension-II & $6(3.0 \%)$ & $3(1.5 \%)$ & $9(2.3 \%)$ \\
\hline \multicolumn{3}{|c|}{ Table 2. Prevalence of Pre-Hypertension and } \\
& Hypertension among Subjects \\
\hline Chi square value= 3.042, p=0.385 & \\
\hline
\end{tabular}

\begin{tabular}{|c|c|c|c|c|}
\hline & Males $(n=200)$ & Females $(n=200)$ & t Value & P Value \\
\hline Righ & $39.26 \pm 2.34$ & $38.61 \pm 2.75$ & 2.544 & 0.011 \\
\hline $\mathrm{Le}$ & $38.07 \pm 2.81$ & $37.18 \pm 3.24$ & 2.919 & 0.004 \\
\hline \multicolumn{5}{|c|}{$\begin{array}{c}\text { Table 3. Comparison of Right and Left ATD Angle } \\
\text { among Males and Females }\end{array}$} \\
\hline
\end{tabular}

\begin{tabular}{|ccccc|}
\hline Blood Pressure & No. & Right ATD Angle & F value & P Value \\
Normal & 250 & $38.75 \pm 2.48$ & & \\
Pre-Hypertension & 113 & $39.03 \pm 2.68$ & 2.472 & 0.061 \\
Hypertension-I & 28 & $40.11 \pm 2.51$ & & \\
Hypertension-II & 9 & $39.22 \pm 3.31$ & & \\
\hline Table 4. Comparison of Right ATD Angle with Blood Pressure \\
\hline
\end{tabular}

Table 4 shows the comparison of right ATD angle with blood pressure among the study subjects. The mean right ATD angle was higher in subjects with Pre-Hypertension $(39.03 \pm 2.68)$, grade I hypertension $(40.11 \pm 2.51)$ and grade II hypertension $(39.22 \pm 3.31)$ compared to subjects with normal blood pressure $(38.75 \pm 2.48)$. The difference in the mean right ATD angle of subjects of different blood pressure categories was however statistically not significant $(\mathrm{p}=0.061)$.

\begin{tabular}{|ccccc|}
\hline Blood Pressure & No. & Left ATD Angle & F Value & P Value \\
Normal & 250 & $37.26 \pm 2.93$ & & \\
Pre-Hypertension & 113 & $37.78 \pm 3.01$ & 7.059 & $<0.001$ \\
Hypertension-I & 28 & $39.89 \pm 3.28$ & & \\
Hypertension-II & 9 & $38.67 \pm 3.74$ & & \\
\hline \multicolumn{2}{|l|}{ Table 5. Comparison of Left ATD Angle with Blood Pressure } \\
\hline
\end{tabular}

Table 5 shows the comparison of left ATD angle with blood pressure among the study subjects. The mean left ATD angle was higher in subjects with Pre-Hypertension (37.78 \pm 3.01), grade I hypertension (39.89 \pm 3.28$)$ and grade II hypertension $(38.67 \pm 3.74)$ compared to subjects with normal blood pressure $(37.26 \pm 2.93)$. The difference in the mean left ATD angle of subjects of different blood pressure categories was statistically highly significant $(\mathrm{p}<0.001)$.

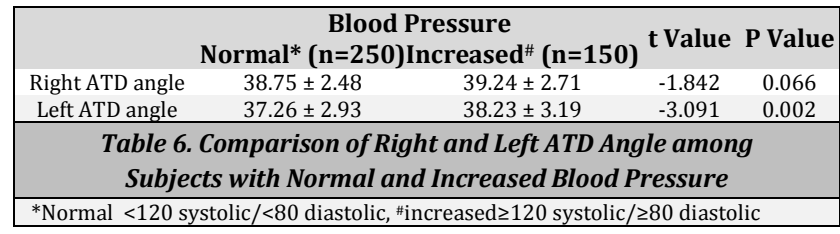

Table 6 shows the comparison of right and left ATD angle in subjects with normal and increased blood pressure. The mean right ATD angle of subjects with increased blood pressure $(39.24 \pm 2.71)$ was higher in comparison to subjects with normal blood pressure $(38.75 \pm 2.48)$ but the difference was statistically not significant $(\mathrm{p}=066)$. Similarly, mean left ATD angle of subjects with increased blood pressure (38.23 \pm 3.19) was higher in comparison to subjects with normal blood pressure (37.26 \pm 2.93) and the difference was statistically significant $(\mathrm{p}=0.002)$.

\begin{tabular}{|c|c|c|c|c|}
\hline & \multicolumn{2}{|c|}{ Right ATD Angle } & \multicolumn{2}{|c|}{ Left ATD Angle } \\
\hline & $\begin{array}{c}\text { r (Correlation } \\
\text { Coefficient) }\end{array}$ & P Value & $\begin{array}{c}\text { r (Correlation } \\
\text { Coefficient) }\end{array}$ & P Value \\
\hline Systolic BP & 0.102 & 0.042 & 0.209 & $<0.001$ \\
\hline Diastolic BP & 0.074 & 0.141 & 0.216 & $<0.001$ \\
\hline \multicolumn{5}{|c|}{ Table 7. Correlation of ATD Angle with Blood Pressure } \\
\hline
\end{tabular}

Table 7 shows the correlation of ATD angle with systolic and diastolic blood pressure of study subjects. A statistically significant positive correlation of ATD angle with systolic blood pressure was observed in both right $(r=0.102$, $\mathrm{p}=0.042)$ and left $(\mathrm{r}=0.209, \mathrm{p}<0.001)$ hand ATD angles of the subjects. However, statistically significant positive correlation of ATD angle with diastolic blood pressure was observed in left hand ATD angle only $(r=0.216$. $p<0.001)$.

\section{DISCUSSION}

Dermatoglyphics has emerged as a useful diagnostic aid in a number of diseases with strong hereditary basis. It is used as a valuable research tool to predict, compare, contrast, to predict the occurrence and risk of health issues related to genetics and medicine. Nowadays many studies have established dermatoglyphic patterns to be associated with various diseases where aetiology is obscure. The purpose is not to diagnose but to prevent by predicting a disease and identify the people with genetic predisposition to develop them. So, the present study was undertaken to find the correlation of ATD angle with blood pressure in north Indian population.

\section{Anthropometric Parameters}

Weight and Height- out of 400 study participants, mean weight was $59.47 \pm 14.44 \mathrm{Kg}$ and mean height was $163.17 \pm$ $8.80 \mathrm{cms}$. Males had significantly higher mean weight out of total number of subjects, $28.3 \%$ were having prehypertension and $9.3 \%$ hypertension. Amongst hypertensive subjects $7.3 \%$ had grade 1 hypertension and $2.3 \%$ were having grade 2 hypertension. Prehypertension was more common in males (31\%) as compared to females $(25.5 \%)$. The prevalence of hypertension was almost similar among males (9\%) and females (9.5\%). The difference in prevalence of prehypertension and hypertension among males and females was not statistically significant $(\mathrm{P}=0.385)$. In India 
the prevalence of hypertension is around $25.30 \%$ in urban and $10-20 \%$ in rural population.(17) As observed in $4^{\text {th }}$ National Family Health survey overall prevalence of hypertension in Haryana is $13 \%$ with $9.2 \%$ in rural and $16.8 \%$ in urban areas.(18) In the study conducted by Malhotra et al. A population-based survey in rural and non-industrial areas in the state of Haryana, India to determine the prevalence of hypertension $5.8 \%$ males and $3 \%$ females were hypertensive.(19) Our study findings were well correlated with the findings of previous studies as it was conducted in rural areas of Haryana. In another study of North India, $32.2 \%$ of population were hypertensive and $32.2 \%$ population had pre-hypertensive.(20)

\section{ATD Angle and Blood Pressure}

On analysis of blood pressure, individuals with normal blood pressure had lowest mean ATD angle in both right and left hands. The mean right ATD angle was higher in subjects with prehypertension $(39.03 \pm 2.51)$, grade 1 hypertension (40.11 $\pm 2.51)$ and grade 2 hypertension $(39.22 \pm 3.31)$ as compared to the subjects with normal blood pressure $(38.75 \pm 2.48)$, however this was statistically not significant $(\mathrm{P}=0.061)$. The mean Left ATD angle was higher in subjects with prehypertension $(37.78 \pm 3.01)$, grade 1 hypertension $(39.89$ \pm 3.28 ) and grade 2 hypertension (38.67 \pm 3.74 )as compared to subjects with normal blood pressure $(37.26 \pm 2.93)$, this difference was statistically highly significant $(\mathrm{P}<0.001)$. With the rise in systolic and diastolic blood pressure an increase in ATD angle of study subjects was observed. A statistically significant positive correlation of ATD angle with systolic blood pressure was observed in both right $(\mathrm{r}=0.102$, $\mathrm{p}=0.042)$ and left $(\mathrm{r}=0.209, \mathrm{p}<0.001)$ hand ATD angle. A statistically significant positive correlation $(\mathrm{r}=0.216, \mathrm{p}<$ 0.001) of ATD angle with diastolic blood pressure was observed in left hand. The mean right ATD angle of subjects with increased blood pressure $(39.24 \pm 2.71)$ was higher in comparison to subjects with normal blood pressure (38.75 \pm 2.48) although this difference was statistically insignificant $(p=0.066)$. The mean left ATD angle was significantly higher ( $p=0.002$ ) among subjects with increased blood pressure $(38.23 \pm 3.19)$ as compared to subjects with normal blood pressure $(37.26 \pm 2.3)$ similar findings were reported by Lahri et al. in 2013 in which mean ATD angle in hypertensive subjects was significantly higher $(\mathrm{p}<0.001)$ that the mean ATD angle in normotensive subjects (44.27 versus 42.3 ).(11)

Our findings are also in consensus with the result of study by Setia A et al. who also observed increase in ATD angle with rising blood pressure. The mean ATD angle in their study amongst normotensive, pre-hypertensive and hypertensive subjects were $37.7,40.1$ and 40.2 respectively. (21) Similarly in another study by Chakravathy PG et al. in 2018, mean ATD angles in right and left hands was significantly higher in hypertensive subjects as compared to normal ones (38.26 versus 35.52 ) and (38.28 versus 35.31) respectively.(22) Many studies have reported higher ATD angle among hypertensive subjects as compared to normotensive individuals, amongst individuals with essential hypertension. $(9,10,11)$ Similar differences have also been observed in studies conducted on subjects with juvenile hypertension.(23,24) In contrast to our findings, Ahmad M et el. observed lower mean ATD angle in hypertensive subjects in comparison to normotensive ones in both right (41.46 vs. 42.18 ) and left hand(41.15 vs. 42.47).(25) In another study by Devi KS et al. mean ATD angle of hypertensive subject was lower compared to controls (45.22 vs. 47.57).(26) Deepa G et al also reported lower mean ATD in hypertensive subjects compared to normotensive.(8) These differences observed are attributed to varying methods employed for measuring ATD angle based on position of axis tri-radius. Further variations in ATD angle may occur as a result of change in pressure applied during printing and whether fingers are closely approximated or splayed.(15) There are growing evidences nowadays about the association of dermatoglyphic traits with hypertension. Various studies suggest an intrinsic association between adult's affliction with hypertension and fetal development of dermatoglyphic features. This association could be explained if the risk towards developing hypertension in later life is somehow connected with intra-uterine expression of dermatoglyphic features. These can be of great utility from clinical point of view if dermatoglyphic markers could be used to screen individuals at higher risk of becoming hypertensive.

\section{CONCLUSIONS}

Pre-hypertensive and hypertensive individuals have higher mean ATD angle than normotensive people. Thus, measurement of ATD angle may be a useful and valuable tool to predict the occurrence of hypertension in individuals who are at higher risk of developing the disease.

\section{REFERENCES}

[1] Holt SB. Dermal patterns in Down's syndrome, Am J of Human Genetics 1961.

[2] Schaumann B, Alter M. Dermatoglyphics in medical disorders. New York: Springer Verlag 1976: p. 187-9.

[3] Rao UN, Easwaran P. Diet counselling - an integral component of hypertension management. The Indian Journal of Nutrition and Dietetics 1990;27:67-76.

[4] Handysides AR, Landless PN. Hypertension. Herald of Health 2005: p. 11-12.

[5] Igbigbi PS, Msamati BC, Ng'ambi TM. Plantar and digital dermatoglyphic patterns in Malawian patients with diabetes, hypertension and diabetes with hypertension. Int J Diabetes and Metabolism 2001;9:24-31.

[6] Kulkarni SKG, Avinash SS, Sreekantha V. Dermatoglyphics in primary hypertensive patients. Int J Pharma Bio Sci 2014;5:53-8.

[7] Bulagouda RS, Patil PJ, Hadimani GA, et al. Study of palmar dermatoglyphics in patients with essential hypertension between the age group of 20-50 years. Int J Med Res Heal Sci 2013;2(4):773-9.

[8] Deepa G. Study of palmar dermatoglyphics in essential hypertension. Natl J Integr Res Med 2013;4(3):61-5.

[9] Tafazoli M, Dezfooli SR, Shahri NM, et al. The study of dermatoglyphic patterns and distribution of the minutiae in inherited essential hypertension disease. Curr Res J Biol Sci 2013;5(6):252-61. 
[10] Oladipo GS, Osogba IG, Bobmanuel I, et al. Palmar dermatoglyphics in essential hypertension amongst rivers indigenes. Aust J Basic \& Appl Sci 2010;4(12):6300-05.

[11] Lahiri A, Bandyopadhyay S, Adhya S, et al. A study on relationship between dermatoglyphics and hypertension. IOSR J Dent Med Sci 2013;7(6):62-5.

[12] Kachhave SK, Solanke PV, Mahajan AA, et al. Dermatoglyphics in the essential hypertension in Marathwada region. Indian J Public Heal Res Dev 2013;4(2):194-8.

[13] Kulkarni DUHN. Dermatoglyphics in essential hypertension in Western Maharashtra population. J Anat Soc India 2005;54:Abstract no 262.

[14] Pursnani ML, Elhence GP, Tibrewala L. Palmar, dermatoglyphics in essential hypertension. Indian Heart J 1989;41(2):119-22.

[15] Mavalwala J. The ATD angle: a critique. Birth Defects Orig Artic Ser 1979;15(6):169-72.

[16] Joint National Committee Report 2004. Prevention, detection, evaluation \& treatment of high blood pressure. 2004.

[17] Gupta R. Trends in hypertension epidemiology in India. J Hum Hypertens 2004;18(2):73-8.

[18] International Institute for Population Sciences (IIPS) and Macro International. National Family Health Survey 4 (NFHS-4), 2015-16.
[19] Malhotra P, Kumari S, Kumar R, et al. Prevalence and determinants of hypertension in an un-industrialized rural population of north India. Journal of Human Hypertension 1999;13(7):467-72.

[20] Yadav S, Boddula R, Genitta G, et al. Prevalence and risk factors of pre-hypertension and hypertension in an affluent north Indian population. Indian Journal of Medical Research 2008;128(6):712-20.

[21] Setia A, Kaur B, Puri N, et al. Palmar dermatoglyphics: mass screening tool for hypertension. Int J Anat Res 2017;5(2.2):3850-4.

[22] Chakravathy PG, Shirali A, Chowta KN, et al. A "Handy" tool for hypertension prediction: dermatoglyphics. Indian Heart Journal 2018;70(Suppl 3):S116-S9.

[23] Polyzová D, Kuklík M, Beránková M, et al Dermatoglyphics in juvenile hypertension. Anthropol Anz 1991;49(4):361-6.

[24] Polat MH, Caner M. Juvenil hipertansiyonla olgularda dcrmatoglifik özellikler. SDÜ Tıp Fakültesi Dergisi 1999;6(2):7-10.

[25] Ahmad M, Pimpalkar DS. Study of palmar dermatoglyphics in hypertension. International Journal of Science and Research 2017;6(3):719-24.

[26] Devi KS, Mahalinga, Savitha. Palmar dermatoglyphics in essential hypertension. IOSR Journal of Dental and Medical Sciences 2016;15(7):27-30. 